\title{
IMAGEN, IDENTIDAD Y TRADUCCIÓN EN LA VERSIÓN TEATRAL ITALIANA DE CINCO HORAS CON MARIO (2017) ${ }^{1}$
}

\author{
IMAGE, IDENTITY AND TRANSLATION IN THE ITALIAN \\ THEATRE VERSION OF FIVE HOURS WITH MARIO (2017)
}

\author{
Nuria PÉREZ VICENTE \\ Universidad de Macerata (Italia) \\ nuria.perezvicente@unimc.it
}

Resumen: La presente comunicación se plantea hacer un estudio, desde un punto de vista pragmático, de las actividades de imagen e identidad en la versión teatral de Cinco horas con Mario, de Miguel Delibes. Se trata de ver cuáles son los actos de habla emitidos por el personaje de Carmen y de estudiar cómo han pasado a la reciente traducción italiana (Delibes, 2017).

Palabras clave: Cinco horas con Mario. Imagen. Actos de habla. Traducción.

\begin{abstract}
The present communication proposes to study, from a pragmatic point of view, the activities of image and identity in the theatrical version of Five Hours with Mario, by Miguel Delibes. We want to see which speech acts are issued by Carmen's character and how they have passed on to the recent Italian translation (Delibes, 2017).
\end{abstract}

Key Words: Five hours with Mario. Image. Speech acts. Translation.

\footnotetext{
${ }^{1}$ Una versión de este artículo se presentó en el XXVII Seminario Internacional Teatro, (auto)biografía y autoficción (2000-2018), celebrado en la UNED (Madrid) los días 2022 de junio de 2018, en homenaje al profesor José Romera Castillo, que dirigió mi tesis de doctorado. A él va dedicado, con todo mi agradecimiento, este trabajo.
} 


\section{PÓRTICO}

En el presente trabajo vamos a ocuparnos de uno de los mejores ejemplos del siglo XX de la literatura del yo: nos referimos a Cinco horas con Mario (de ahora en adelante 5HM), de Miguel Delibes (1966), que aquí estudiaremos en su versión teatral. No es esta, como sabemos, una autobiografía ad hoc sino un relato autobiográfíco de ficción que se ajusta por completo al formato de escritura autobiográfica ${ }^{2}$. Además, y como veremos a lo largo de este trabajo, la obra contiene diversos niveles autobiográficos.

Nos basaremos en la única traducción italiana de la adaptación teatral $^{3}$, realizada recientemente por Renata Londero (2017) para la editorial Marsilio de Venecia. No entraremos en esta sede en la relación entre novela y texto dramático — aspecto largamente estudiado ${ }^{4}$ - del cual este último es lógicamente una síntesis y condensación, pero sí nos interesa destacar que es una de las tres obras narrativas que el autor adaptó al teatro, y que de ellas es posiblemente la que más éxito ha tenido: su gran fuerza dramática, concentrada en la voz femenina, así como la ausencia de narrador, el predominio de la oralidad y la simplicidad de escenarios (uno solo), han favorecido sin duda que así sea. De hecho, la obra se representa, con pocas interrupciones, desde 1979, protagonizada por Lola Herrera (en lo que seguramente ha sido el papel de su vida) y de 2010 a 2014 por Natalia Millán 5 .

\footnotetext{
${ }^{2}$ Sobre autobiografía, y concretamente sobre relato autobiográfico de ficción, vid. Romera Castillo $(1981,2004)$ y De Castro (1993). Y sobre aspectos autobiográficos en la obra de Delibes, cf. Romera Castillo (2006, 2010). En el Centro de Investigación de Semiótica Literaria, Teatral y Nuevas Tecnologías (SELITEN@T), dirigido por el prof. Romera, se pueden encontrar numerosos trabajos al respecto, fruto de una sólida y duradera labor de investigación, como puede verse en http://www2.uned.es/centro-investigacionSELITEN@T/escritura_autobio.html [20/05/2018].

${ }^{3}$ Adaptación del propio Delibes de la que existen dos versiones, una de 1979 y otra de 2001, realizadas en colaboración con José Sámano y Josefina Molina. Se publica dos veces: en edición de González Sobejano (Delibes, 1981) —es la versión usada por Londero en su edición bilingüe, por tanto la nuestra - y en Obras Completas (Delibes, 2010).

${ }^{4}$ Basten como ejemplo Sobejano (1981), Amorós (1993), Tabernero (1987), Valles Calatrava (2004) y Perugini (2016). Más bibliografía en Londero (2017: 173-176).

${ }^{5}$ Para lo concerniente a la representación de la obra teatral, en España y en el extranjero,
} 
El texto, que consta de un solo acto, se compone casi por completo del largo discurso de Carmen, que en la más pura tradición de autobiografía femenina se desarrolla como flujo de conciencia, usando la técnica de la libre asociación de ideas. Pero no se trata de un monólogo, ya que hay un interlocutor preciso: Mario, el marido muerto que Carmen velará durante cinco interminables horas. Para Alfonso Rey (1975) es un diálogo con interlocutor ficticio, y el propio Delibes (Alonso de los Ríos, 1993: 106) decía de él que, más que un monólogo interior, era un diálogo interior. Esta es sin duda la mayor originalidad de un texto que, por todo ello, vamos a considerar un soliloquio. Y es que la presencia de Mario es constante a lo largo del texto, como constantes son los elementos fáticos que sirven para mantener el contacto con él: los imperativos, las preguntas, los vocativos, los verbos en presente que nos hacen pensar en un oyente vivo, dispuesto a reaccionar a las imprecaciones de Carmen.

En cambio, y por razones obvias, Carmen no obtendrá ninguna respuesta, como tampoco las obtuvo en vida de su marido. Porque el soliloquio, forma extrema de la incomunicación (Londero, 2014: 463), sirve a Delibes para demostrarnos la ruptura entre lo que, tradicionalmente, se han considerado las dos Españas: la de él, intelectual, librepensador, antifranquista y poco amigo de las convenciones sociales; la de ella, provinciana y llena de prejuicios, preocupada sobre todo por las apariencias, representante de la sociedad conformista de los años sesenta que, en plena dictadura, aspira a poseer cierto estatus social. La obra, a través de una ironía que permea el texto hasta el punto de ser la base de su esquema constitutivo (porque qué mayor ironía que la de dialogar con un muerto) ${ }^{6}$, acabará convirtiéndose en una crítica de esta sociedad, al revalorizar el punto de vista del ausente, de Mario.

En esa larga noche Carmen recuerda su vida en común y pasa revista a sus desaveniencias conyugales, que provienen de la diferente visión de la vida que ambos tienen. Su soliloquio se construye a través de una sarta de convencionalismos y frases hechas que pretenden reafirmar y

remitimos a la Fundación Miguel Delibes (http://www.fundacionmigueldelibes.es) y a Londero (2017). La temporada 2018/2019 cuenta otra vez con Lola Herrera como protagonista (http://sabreproducciones.com/teatro-obras/cinco-horas-con-mario-3aversion $[10 / 05 / 2018])$.

${ }^{6}$ Sobre la ironía en $5 H M$ ver entre otros Bottaro (2001), Martínez (1992) y García García (2003). 
reparar su lastimado yo. Solo en las últimas páginas descubrimos que los reproches que Carmen lanza a su marido sirven en realidad a otra finalidad aún mayor: la de justificar su conducta $\mathrm{y}$, en última instancia, pedirle perdón por una traición cometida, confesada, como decimos, solo al final del texto.

Nuestro propósito en el presente trabajo, basándonos en las teorías de la cortesía de Brown y Levinson (1978) — que reelaboran a su vez el concepto de imagen de Goffman (1967) - es ver cuáles son los actos de habla emitidos por el personaje de Carmen y las operaciones de (des) cortesía que estos generan, para estudiar cómo han pasado a la traducción italiana ${ }^{7}$. Goffman (1967) se basa en la idea de que, cuando participamos en un intercambio discursivo, todos queremos que nuestra imagen sea valorada, respetada y aprobada por los demás. La cortesía, principio básico de la dinámica comunicativa, sirve precisamente para preservar esta imagen y contrarrestar los FTA (face threatening act) o actos de amenaza a la imagen que puedan surgir en la interacción (Brown y Levinson, 1978). Aparte de una cortesía normativa o convencional, para la que tenemos buena cantidad de fórmulas socialmente aceptadas, existe - y esa es la que aquí nos interesa - una cortesía estratégica (Bravo, 2001) que se define a partir de la finalidad con que se emplea. Es decir: todo hablante usa los mecanismos discursivos adecuados para que su imagen quede preservada y su mensaje resulte comunicativamente eficaz.

\footnotetext{
${ }^{7}$ No es nuestra intención hacer un estudio de la densa coloquialidad del texto, sino solo de aquellas estrategias que nos ayuden a entender los mencionados actos. Del mismo modo, nos centraremos en el soliloquio, y no en las partes polifónicas — con las voces de otros personajes - del principio y del final.

${ }^{8}$ Utilizamos aquí las teorías de Brown y Levinson aun a sabiendas de que han sido largamente criticadas, en primer lugar por su presunto carácter universal; en segundo, por una visión excesivamente negativa de la interacción humana, que parece así responder solo a continuas amenazas. Pero, aunque hipótesis posteriores relacionadas con la pragmática sociocultural superen su planteamiento - en el ámbito hispano nos gustaría citar, a modo de ejemplo, a Bravo (1999, 2001, 2003) y Hernández Flórez (2002)_, lo cierto es que siguen considerándose las más clásicas, punto de partida insustituible — como afirma Kerbrat-Orecchioni (1997)— de cualquier estudio sobre cortesía. Además, en este caso nos interesa una fuente teórica que, al basarse en la idea de imagen de Goffman, estudie la cortesía desde una perspectiva no estrictamente sociocultural, lo cual nos parece adecuado para afrontar un texto que se centra en la emotividad del personaje femenino protagonista.
} 
Centrándonos en el caso que nos ocupa, hay que decir que el soliloquio de Carmen es altamente reprobatorio. Pero, para poder hacer valer sus argumentos y, sobre todo, para alcanzar la última finalidad del discurso que, como hemos visto, es la de excusarse (y a la vez justificarse) ante su marido, debe salvar también la imagen de este último. Porque si la imagen de Mario fuera dañada o destruida (si Carmen lo atacara abiertamente), el soliloquio perdería validez. No sería más que el ataque verbal a un enemigo. Sin embargo, repetimos, Carmen debe obtener algo de él: debe ser comprendida para, a continuación, ser — hipotéticamenteperdonada. Por eso necesita un interlocutor ya que, como afirma Goffman (1967), la imagen se construye en la interacción con el otro.

Consideramos, por tanto, que hay fundamentalmente dos actos de habla en este soliloquio: el de reprobación y el de exculpación. Haciendo uso de una cortesía mitigadora, que intentará reparar y compensar los posibles daños a su imagen, Carmen se ve en la necesidad de usar de forma equilibrada recursos de intensificación, para reafirmar su discurso y desvalorizar el de Mario (para ponerle en su sitio, podríamos decir); y de atenuación, para reducir el valor de los argumentos contrarios a su forma de pensar y mitigar su fuerza ilocutiva. De esta forma se alivian las posibles tensiones que podrían afectar al efectivo intercambio comunicativo y se salvaguarda la imagen de ambos interlocutores. Como decíamos, Carmen necesita valorar a su receptor para que le sirva de real contrapunto, por eso encontraremos también, aunque en menor medida, una cortesía valorizadora de tipo indirecto que lo halaga a través de una ficticia colaboración discursiva.

Pasemos entonces a estudiar estos dos actos de habla y los mecanismos de intensificación y atenuación en que se apoyan, para comprobar si la versión italiana mantiene los mecanismos dialogales y su fuerza ilocutiva, proporcionando al texto una representabilidad y recitabilidad análoga.

\section{LA REPROBACIÓN}

El soliloquio está poderosamente marcado por la deixis personal: la repetición continua de los pronombres y vocativos, sirven, por una parte, para dejar claro quiénes son los dos interlocutores y mantener la ficción dialogal, acentuando lo irónico de la situación. Por otra parte, se relacionan 
directamente con el acto de reprobación porque ayudan a Carmen a reafirmar su yo y justificar su comportamiento, distanciándose de ese tú antagonista que le sirve de contrapunto. Por eso el texto está plagado de reafirmativas en primera persona, así como de imperativos o enfocadores de alteridad (Londero, 2014: 472) que Carmen repite hasta la saciedad y no sirven (como es obvio) para llamar la atención del interlocutor y buscar su acuerdo - "entiendes", "fíjate", "comprendes" - sino que, convertidas en armas arrojadizas, le reprochan que es precisamente eso (entender, fijarse, comprender) lo que no ha hecho en vida. Así arranca el soliloquio de Carmen':

Y ahora que empiezan las complicaciones, querido, zas, adiós muy buenas, como la primera noche, ¿recuerdas?, te vas y me dejas sola tirando del carro. Y no es que me queje, entiéndelo bien, que peor están otras; mira Transi, imagínate, con tres criaturas; pero me da rabia, la verdad, que te vayas sin reparar en mis desvelos, sin una palabra de agradecimiento [...]. Los hombres, por regla general, una vez que os echan las bendiciones, a descansar, un seguro de fidelidad, como yo digo (82).

E ora che iniziano le complicazioni, caro mio, puf, tanti saluti, come la prima notte, ti ricordi?, te ne vai e mi lasci lì da sola a tirare la carretta. E, sia chiaro, non è che mi lamenti, altre stanno peggio; guarda Transi, pensa un po', con tre creature, ma mi fa rabbia, davvero, che tu te ne vada senza tener conto delle mie preoccupazioni, senza una parola di ringraziamento [...]. Voi uomini, di norma, dopo che vi hanno dato la benedizione, belli tranquilli, un'assicurazione sulla vita, come dico io (83).

Es notorio lo irónico de la situación: Carmen reprocha a Mario que se haya muerto sin avisar. El acto de habla reprobatorio está lleno de intensificaciones que lo apoyan. La segunda persona es interpelada directamente, a menudo con un vocativo ("Mario"), con el apreciativo "querido", a través de un imperativo ("entiéndelo bien", "mira",

${ }_{9}^{9}$ Las páginas de los ejemplos, entre paréntesis, pertenecen al volumen bilingüe empleado (Delibes, 2017). 
"imagínate") o de una frase interrogativa ("¿recuerdas?"). Del mismo modo, hay una clara presencia del yo ("me dejas sola", "y no es que me queje", "me da rabia", "mis desvelos") que se confirma en la reafirmativa en primera persona ("como yo digo"). Otros elementos como la onomatopeya ("zas"), de gran efecto teatral, o la fraseología ("adiós muy buenas"), sirven a los mismos fines. Para reafirmar sus argumentos, Carmen se apoya en voces externas. A veces utiliza simples expresiones evidenciales ("la verdad"); otras recurre, como aquí, al concierto de la mayoría ("por regla general") y, en muchos casos, incluye como discurso referido lo expuesto por aquellos que para ella poseen mayor autoridad: la madre ("que tenía un ojo clínico"), el padre, su amiga Transi, y en general todos aquellos que considera superiores (el director del instituto, la policía, etc.).

Pero no hay que olvidar, como decíamos, que el discurso de Carmen necesita de la atenuación para poder reprobar sin perder la posibilidad de exponer sus argumentos. Uno de los mecanismos de atenuación más frecuente es la lítote, que podemos definir como "ironía perifrástica por disimulación, en cuanto que un grado superlativo es transcrito por la negación de lo contrario" (Lausberg, 1975: 112). La lítote se relaciona con la hipérbole, y por tanto con la intensificación, ya que al negar su contrario, amplía hasta un límite insospechado la valoración del término. Hay muchos ejemplos en $5 H M$ asociados a oraciones adversativas, que constituyen otro importante mecanismo de atenuación pues mitigan la aserción, como "y no es que yo me queje, pero...". La queja de Carmen no solo se manifiesta igualmente, sino que se intensifica.

La traducción reproduce perfectamente el acto reprobatorio, con elementos intensificadores y atenuadores. Se mantiene el apreciativo ("caro mio"), la onomatopeya ("puf"), los imperativos ("guarda", "pensa un po"”) y la interrrogación ("ti ricordi?"), la expresión evidencial ("davvero") y la fórmula de reafirmación ("come dico io"). Un hipérbaton resalta el elemento anticipado ("sia chiaro") sin perder la lítote, que conserva su estructura adversativa ("non è che mi lamenti, ma...”). La sustitución del imperativo ("entiéndelo bien") por "sia chiaro" es producto, como explica Londero (2017: 60), de la necesaria flexibilidad traductiva destinada a conservar la tensión dramática y a restituir de modo fluido el densísimo continuum discursivo de Carmen.

El acto reprobatorio se manifiesta no pocas veces a través de la descalificación directa, es decir, del insulto. Pero se trata de insultos 
menores y matizados, destinados no tanto a herir al adversario como a demostrar su inhabilidad y poca comprensión respecto a la postura de Carmen, defendida como única posible. En el siguiente fragmento, por ejemplo, la mujer intenta convencer a Mario de lo improcedente de usar la bicicleta en vez del coche. Para ello se apoya en las habituales reafirmativas ("te lo juro", "me parece a mí" / "te lo giuro", "mi sembra"), en imperativos (“desengáñate" / "svegliati") y en la lítote ("no te digo yo que [...], pero..." / "io non dico che [...], ma..."), que se mantienen en italiano:

Desengáñate, Mario, cariño, la bici no es para los de tu clase, que cada vez que te veo en ella se me abren las carnes, te lo juro, [que] la categoría obliga, tonto de capirote, y un catedrático de Instituto, no te digo yo que sea un ingeniero, pero es alguien, me parece a mí... (92).

Svegliati, Mario mio, la bici non è per la gente della tua classe: ogni volta che ti ci vedo mi si drizzano i capelli, te lo giuro [...]. Ogni categoria ha le sue regole, sciocco che non sei altro, e un professore di liceo, io non ti dico che sia un ingegnere, ma è qualcuno, mi sembra... (93).

El campo léxico utilizado es el de "tonto" y sus sinónimos. A veces, como en este caso ("tonto de capirote"), el término se amplia con un elemento que, aun intensificándolo, contribuye a dar un toque de humor, quitándole importancia. La traducción mantiene el mismo tono a través de una estructura coloquial — "sciocco che non sei altro"—- ${ }^{10}$. El apreciativo "cariño", intercalado continuamente y traducido normalmente por términos de frecuencia similar en italiano como "tesoro" o "caro", se convierte aquí en una intensificación del vocativo ("Mario mio") que añade ironía al texto. Notamos, sin embargo, que los apreciativos, más que cumplir una función valorativa, suelen servir de atenuante cuando los reproches se hacen más evidentes. En el siguiente ejemplo el aparente elogio de Carmen, aderezado con el apreciativo "querido" e intensificado con una fórmula léxica ("te

\footnotetext{
${ }^{10}$ Otros términos empleados y su traducción son "zascandil" (98) / "tontolone" (99), "furbone" (123); "grandísimo alcornoque" (104) / "zuccone che non sei altro" (105); "tonto del higo" (120) / "testa di rapa" (121).
} 
lo digo y te lo repito"), está en realidad tamizando una crítica: la de que Mario escribe cosas poco interesantes, incluso incomprensibles - "icon lo que a mi me gustaría que escribieses libros de amor!", exclama Carmen-. Nótese que tal crítica hace uso de otros procedimientos de atenuación, concretamente a través de la fraseología usada con valor eufemístico ("no sé qué maña te das", "ni escogidos con candil", "me quedo in albis"), que sirve para introducir un circunloquio que diga sin decir. La traducción realiza una pequeña amplificación clarificadora ("l'unico difetto") y se sirve de fórmulas fraseológicas con la misma finalidad ("dove le tiri fuori", "a cercarle con lanternino", "io resto a bocca aperta"):

Porque tú sabes escribir, querido, te lo digo y te lo repito; lo único, los argumentos, que no sé qué maña te das, que ni escogidos con candil. Eso cuando se te entiende, que cuando te pones a hablar de estructuras, plusvalías y cosas de esas, me quedo in albis, te lo prometo... (90).

Perché tu sai scrivere, caro, qui lo dico e lo ripeto; l'unico difetto, le trame, che non so da dove le tiri fuori, neanche a cercarle col lanternino. E questo quando ti si capisce, perché quando cominci a parlare di strutture, plusvalore, e cose del genere, io resto a bocca aperta, ti giuro... (91).

El hablante, para reafirmar su ego, se sirve de recursos de naturaleza fónica y entonativa, connaturales al aspecto escénico del texto dramático, que se manifiestan por signos de exclamación y de interrogación. Estos últimos a veces son simples elementos de atención, marcadores fáticoapelativos que parecen querer despertar al Mario dormido — “eh?”, “¿no?”-, conservados en la traducción; otras son verdaderas interrogativas retóricas que interpelan a bocajarro a un Mario que no puede, obviamente, responder - “Mírate en mi espejo, ¿ofendo yo?, no, ¿verdad?” (122) / "Guardami negli occhi, io offendo?, no, vero?" (123)—, y forman parte del acto reprobatorio; a veces se encadenan unas a otras en largas series, como en el siguiente ejemplo:

¿Tú crees que un cristiano puede decir a boca llena, en plena clase, que fue una lástima que la Iglesia no apoyase a la Revolución 
francesa ¿Te das cuenta de lo que dices?, ¿es que estás en tus cabales, Mario, una blasfemia así? ¿Pues no era la Revolución francesa aquella de las tiorras desgreñadas que cortaban la cabeza al rey y a las monjitas y a toda la gente buena, la de Pimpinela Escarlata o eso? Vamos, que se necesita cuajo para decir una cosa asi (126).

Tu credi che un cristiano può dire senza mezzi termini, a lezione, che è stato un peccato che la Chiesa non abbia appoggiato la Rivoluzione francese? Ti rendi conto di quello che dici? Sei tutto giusto, Mario? Ma che eresia è? La Rivoluzione francese non era quella delle tizie esagitate che tagliavano la testa al re e alle suorine e a tutta la brava gente, quella della Primula Rossa o roba del genere? Dai, ci vuole fegato per dire una cosa simile (127).

La serie de interrogativas encierra los mecanismos reprobatorios ya vistos, conservados en la traducción: el tú inicial interpelador, el vocativo, la interjección impropia "vamos" con valor de rechazo e indignación (Cascón, 2000: 22), o las preguntas de reconvención en segunda persona (Cascón, 2000: 77) — “ite das cuenta?” / “ti rendi conto?”-, que ponen de manifiesto el comportamiento inadecuado del interlocutor, con una acusada carga irónica. Nótese también cómo Delibes reproduce los enunciados concatenados y la elipsis (que hemos señalado entre corchetes) propios del lenguaje oral: “¿es que [no] estás en tus cabales, Mario, [decir] una blasfemia así?” / "sei tutto giusto, Mario? ¿Ma che eresia è [questa]?”. La traducción usa elisiones y estructuras sintéticas muy coloquiales. Otras estrategias léxicas de intensificación — la sufijación despectiva en "tiorras" y el diminutivo afectivo "monjitas" — se trasladan al italiano con idéntico mecanismo ("suorine") o por medio de compensación coloquial ("tizie").

Dos son las fuerzas que, subrepticiamente, movilizan a Carmen, y que Martín Gaite (1993) sintetiza con precisión en el binomio "sexo y dinero". De hecho, Carmen recrimina a Mario por su tacañería - no le ha querido comprar el seiscientos, síntoma de bienestar burgués- y por su escasa pasión sexual (que ella asocia con su aparente desatención en la noche de bodas). Tales reproches no dejan de ser un modo de justificar su comportamiento, es decir, el amago de traición que dará lugar al segundo acto de habla: 
Pero no es solo la noche de boda, Mario, que un poquitín más de pasión no te hubiera venido mal. Que siempre te mostraste muy apático conmigo. Mucho "amor mio", mucho "mi vida" y, luego, nada entre dos platos (102).

Ma non è stata solo la prima notte di nozze, Mario, una briciola in più di passione non avrebbe guastato. Sei stato sempre apatico con me. Tanto "amor mio", tanta "vita mia", e stringi stringi, non si stringeva niente (103).

Junto a la lítote encontramos otros recursos típicos de la atenuación, como los cuantificadores minimizadores ("solo", "poquitín") que difuminan el significado pleno del término al que acompañan. Todo ello se contrarresta con las intensificaciones ("muy", "mucho") y la fraseología eufemística ("nada entre dos platos"), ejemplo de ambigüedad semántica que Martín Gaite (1993) define de confesionario, habitual en el lenguaje de la época y más cuando concernía a temas tabú, como el sexo. La traducción no pierde la fuerza pragmática aportada por los numerosos recursos: mantiene la adversativa aunque evita el "que" pleonástico coloquial (Londero 2014: 467), que habría sido innatural en italiano. Los cuantificadores e intensificadores se conservan o se ponderan a través de elementos léxicos coloquiales ("una briciola in più") que recogen el sentido minimizante. En relación a las unidades fraseológicas, a pesar de ser español e italiano dos lenguas afines, la isomorfía es escasa (Londero: 2017), por lo cual el criterio prevalente ha sido el de conservar la equivalencia pragmática. El uso de un elemento no fraseológico, sino retórico (un políptoton) - “stringi stringi, non si stringeva niente"-, recoge perfectamente la ironía y el tono eufemístico de la expresión, manteniendo el registro coloquial ${ }^{11}$. El discurso referido - en este caso las, según ella, inútiles efusiones verbales de Mario: "amor mío", "mi vida", etc.—, además de poseer una gran fuerza dramática que confirma el carácter teatral del texto, reproduce el discurso de Mario vivo para negarlo ${ }^{12}$.

\footnotetext{
${ }^{11}$ La iteración se demuestra muy productiva para recuperar la carga connotativa del TO. También en este caso: "que yo achicada" (84) / "e io lì, piccola, piccola" (85).

12 Otro ejemplo lo tenemos cuando Carmen le reprocha no tener en cuenta el método de
} 


\section{LA EXCULPACIÓN}

Carmen necesita pedir perdón a Mario por su pseudo-traición con un antiguo pretendiente, Paco, que seduce a Carmen con los dos argumentos que, como hemos visto (Martín Gaite, 1993), más la conmueven: el sexo (es un hombre guapo, varonil) y el dinero (tiene un Tiburón, un magnífico coche deportivo). Aunque ocupa solo las últimas páginas, la escena da sentido al resto del texto, y a su luz entendemos que lo que ha hecho Carmen hasta entonces es tratar de justificarse ${ }^{13}$, considerando la conducta de Mario (su desatención, su egoísmo) causa directa de dicha traición. Es más, le horroriza el hecho de pensar que Mario, yéndose sin avisar, pueda dejarla sin el perdón manifiesto que necesita para acallar su conciencia. Porque, más que perdón, lo que Carmen busca es una absolución.

Antes veíamos cómo los numerosos marcadores de alteridad, más allá de la habitual función apelativa, mantenían las distancias con el interlocutor. Todo cambia en esta última parte del texto, en la que dichos marcadores recuperan su verdadera función pragmático-semántica vehiculando el verdadero estado de ánimo de la protagonista. El texto se transforma en una acumulación de imperativos e interjecciones que apelan sin cesar a la segunda persona. Carmen busca la real comprensión de Mario y, a la vez que se justifica, quita importancia a su traición y la achaca a diferentes factores, sobre todo de índole física:

[...] como lo estás oyendo, que estaba como hipnotizada, te lo juro, y luego aquel olor entre de colonia y tabaco rubio, que transtorna a cualquiera, que yo solo te quiero a ti, no hace falta que te lo diga, pero estaba como atontada, a lo mejor de la misma velocidad, la

contracepción Ogino-Knaus: “[...] y luego de repente, zas, el antojo, en los peores días, en plena ovulación... 'no seamos mezquinos con Dios', 'no mezclemos las matemáticas en esto...’ ¡Ja! ¡Qué facilito!, ¿verdad?” (88). La traducción conserva el mecanismo: “[...] e poi, di colpo, zac, la voglia, nei giorni peggiori, in piena ovulazione... 'non siamo meschini con Dio', 'non mescoliamo la matematica con quello'. Ahah! Facile, eh?" (89). Nótese el importante papel pragmático-irónico de la interjección "ja" / "ahah".

13 Delibes, refiriéndose a la novela, afirma: “Todo el soliloquio está construido en función de ese último capítulo [...]. Todos los reproches [...] aspiran a ser una justificación de su caída, una justificación de sí misma” (Alonso de los Ríos, 1993: 75). 
falta de costumbre, vete a saber (144).

[...] credimi, era come se fossi ipnotizzata, te lo giuro, e poi quell'odore di colonia e tabacco biondo mescolati, che fa girar la testa a qualunque donna, io voglio bene solo a te, non serve che te lo dica, ma ero come rimbecillita, forse per la rapidità del gesto, la mancanza di abitudine, va' a sapere (145).

La traducción respeta las llamadas a la segunda persona y emplea los mismos recursos del texto original: imperativos ("credimi"), reafirmativas en primera persona ("non serve che te lo dica", "te lo giuro"), apelaciones a la segunda ("va' a sapere"), además de elementos fraseológicos que recogen e intensifican el sentido pragmático del original ("che fa girar la testa a qualunque donna"). Disentimos en cambio de la traducción en lo referente al término "velocidad": Carmen se refiere, creemos, a la del coche de Paco — donde tiene lugar la escena—, no a la del gesto.

Los recursos se intensifican en la última página. El tono discursivo se alza fuertemente, de lo cual dejan constancia las dobles exclamaciones. La apelación a la segunda persona alcanza vetas inusitadas, ya que Carmen pide a Mario una imposible e inmediata respuesta física a sus súplicas. La ironía llega a su cumbre y, dentro del fuerte dramatismo, alcanza un tono casi caricaturesco. De especial significado el imperativo final "anda", que recobra (paradójicamente) su valor de movimiento.

Mario, mírame un poco, di algo, no te quedes ahi parado, que parece que no me creyeras [...]. Mario, anda, te lo pido de rodillas, no hubo más, te doy mi palabra, que yo solo he sido para ti, te lo juro, te lo juro por lo más sagrado! [...]. i¡Te lo juro, mírame!! iique me muera si no es verdad!!, pero no te encojas de hombros, por favor, mírame, de rodillas te lo pido, anda, que no lo puedo resistir, no puedo, Mario, te lo juro, imírame o me vuelvo loca! i;Anda, por favor!! (148).

Mario, guardami un momento, di' qualcosa, non restare lì impalato, sembra che non mi credi [...]. Mario, dài, te lo chiedo in ginocchio, non ci fu altro, ti do la mia parola, io sono stata solo tua, te lo giuro per quanto ho di più sacro [...], te lo giuro, guardami!, possa 
morire se non è vero!, ma non dare un'alzata di spalle, per favore, guardami, in ginocchio te lo chiedo, ti prego, non ce la faccio proprio, no, Mario, te lo giuro, guardami o divento pazza! Per favore, ti supplico! (149).

La traducción mantiene los recursos de intensificación y emplea exclamaciones (aunque en menor medida), vocativos, numerosos imperativos ("guardami", "dài", "non restare lì impalato", "non dare un'alzata di spalle"), constantes fórmulas performativas ("te lo giuro") y potentes apelaciones a la segunda persona ("te lo chiedo", "ti prego", "te lo chiedo in ginocchio") que compensan el valor de movimiento de ciertos imperativos ("anda" / "ti supplico").

\section{CONCLUSIONES}

En el largo discurso de Carmen predominan dos actos de habla: el reprobatorio y el exculpatorio. Solo al final del texto entendemos que el primero se construye en función del segundo, ya que sirve al emisor para justificar su conducta. Ambos actos se apoyan en un perfecto entramado lingüístico que se manifiesta a través del redundante, e incluso exasperante, discurso de Carmen, cuya finalidad es la de reafirmar a toda costa su imagen para que el mensaje, y con él su justificación, resulte comunicativamente eficaz. Para ello utiliza de forma equilibrada recursos de intensificación y de atenuación. La traducción italiana de la obra usa muy adecuadamente análogos mecanismos lingüísticos y retóricos que mantienen la fuerza ilocutiva del original y producen la ilusión dialogal que el texto exige. Todo ello con una flexibilidad traductiva que respeta el criterio targed oriented elegido por la traductora, único posible al tratarse de una obra teatral destinada a representarse en los escenarios italianos.

Es precisamente esta repetición hiperbólica y egocéntrica la que nos da la pista de que $5 H M$ se construye en torno al eje de la ironía. Delibes mismo reconoce haber cargado de forma consciente las tintas del personaje, rozando el límite de la caricatura ${ }^{14}$. La ironía contribuye a delimitar el

\footnotetext{
14 "Si yo no hubiera concentrado tantos defectos, si la caricatura hubiera sido más piadosa, quizá la fuerza aleccionadora del libro hubiera sido mayor" (Alonso de los Ríos, 1993: 77).
} 
alcance autobiográfico del texto, que presenta tres niveles. El primer nivel autobiográfico es, evidentemente, el de Carmen, quien a través de su discurso nos desvela frustraciones y deseos que ella misma ignora. Pero tal discurso, insertado en una estructura irónica "de sustitución" (Bottaro, 2001: 22) que revaloriza la personalidad que aparentemente critica, es por ello y sobre todo la autobiografía del otro, es decir, de Mario, retratado perfectamente a través del soliloquio de Carmen. Se trata de una estructura muy pensada que requiere una gran estabilidad de referentes para que el lector, convenientemente guíado, sepa en todo momento reconocerlos ${ }^{15}$. Por último, encontramos en $5 H M$ la autobiografía del propio autor, de Delibes, quien a través de la identificación positiva con Mario, logra comunicarnos un mensaje profundamente ético que revela un alto grado de sí mismo ${ }^{16}$. En palabras de Francisco Umbral (1970), Delibes demuestra aquí su ventriloquismo literario, es decir, su fabulosa capacidad para poner voz a los personajes y expresarse a través de ellos.

\section{REFERENCIAS BIBLIOGRÁFICAS}

ALONSO DE LOS RÍOS, C. (1993). Conversaciones con Miguel Delibes. Barcelona: Destino.

AMORÓS, A. (moderador); HERRERA, L.; SACRISTÁN, J.; IBÁÑEZ MENTA, N. y SÁMANO, J. (participantes) (1993). "De la novela al teatro" [Mesa redonda]. En Miguel Delibes. Premio Letras Españolas 1991, Ministerio de Cultura (ed.), 259-274. Madrid: Ministerio de Educación, Cultura y Deporte.

BOTTARO, M. G. (2001). "La ironía como artificio constructivo en Cinco horas con Mario de Miguel Delibes". Gramma 13.34, 2033 (también en https://p3.usal.edu.ar/index.php/gramma/article/ view/349 [12/01/2019]).

\footnotetext{
${ }^{15}$ De hecho Delibes explica que en su primera redacción la novela era dialógica y contaba con un Mario vivo, pero así el texto no hubiera soportado la censura. De este modo, en cambio, al ser los argumentos expuestos los defendidos por el régimen, el texto resultaba difícilmente sancionable.

${ }^{16} \mathrm{El}$ autor reconoce desdoblarse en sus obras: "Yo traslado a mis personajes los problemas y angustias que me atosigan, o los expongo por sus bocas. En definitiva, uno, si es sincero, se desdobla en ellos" (Alonso de los Ríos, 1993: 56).
} 
BRAVO, D. (1999). “¿Imagen positiva vs. imagen negativa?: pragmática socio-cultural y componentes de face". Oralia 2, 155-184. (2001). "Sobre la cortesía lingüística, estratégica y conversacional en español”. Oralia 4, 299-314.

(2003). "Actividades de cortesía, imagen social y contextos socioculturales: una introducción”. En Actas del Primer Coloquio EDICE. La perspectiva no etnocentrista de la cortesía: identidad sociocultural de las comunidades hispanohablantes, D. Bravo (ed.), 98-108. Estocolmo: Universidad de Estocolmo. Libro-e.

BROWN, P. \& LEVINSON, S. (1978). "Universals in Language Use: Politeness Phenomena”. En Questions and Politeness. Strategies in Social Interaction, E. N. Goody (ed.), 56-289. Cambridge: Cambridge University Press.

CASCÓN, E. (2000). Español coloquial. Rasgos, formas y fraseología de la lengua diaria. Madrid: Edinumen.

DE CASTRO, I. (1993). "Novela actual y ficción autobiográfica". En Escritura autobiográfica, J. Romera Castillo (ed.), 153-158. Madrid: Visor Libros.

DELIBES, M. (1966). Cinco horas con Mario. Barcelona: Destino.

(1981). Cinco horas con Mario. Versión teatral, G. Sobejano (ed.). Madrid: Espasa-Calpe.

(2010). Cinco horas con Mario. Versión teatral. En Obras Completas VI, 773-804. Barcelona: Destino.

(2017). Cinque ore con Mario. Versione teatrale, R. Londero (ed.). Venezia: Marsilio.

DE PIERI, M. T. (2014). "Cinco horas con Mario a teatro: riflessioni traduttive per un adattamento in lingua italiana". Estudios de Traducción 4, 79-97 (también en https://revistas.ucm.es/index.php/ ESTR/article/view/45369 [15/01/2019]).

(2015). "Tra dissimulazione e ironia: la voce discreta di Miguel Delibes". En Miguel Delibes. Itinerari di vita e scrittura, R. Londero y M. T. De Pieri (eds.), 69-90. Padova: Linea.

GARCÍA GARCÍA, P. (2003). "La ironía del demiurgo en Cinco Horas con Mario". En La ironía en la narrativa hispánica contemporánea, VV. AA, 179-188. Puerto de Santa María: Fundación Juan Goytisolo.

GOFFMAN, E. (1967). Interaction Ritual. Essays on Face-to face Behaviour. New York: Pantheon Books. 
HERNÁNDEZ FLÓREZ, N. (2002). La cortesía en la conversación española de familiares y amigos. La búsqueda de equilibrio entre la imagen del hablante y la imagen del destinatario. Aalborg: Universidad de Aalborg.

KERBRAT-ORECCHIONI, C. (1997). "A Multilevel Approach in the Study of Talk-in-interaction". Pragmatics, 7/1, 1-20.

LAUSBERG, H. (1975). Elementos de retórica literaria. Madrid: Gredos. LONDERO, R. (2014). "L'adattamento teatrale di Cinco horas con Mario di Miguel Delibes (1979): questioni e proposte traduttive". En La traduzione. Opere e autori del Novecento, L. Dolfi (ed.), 459-476. Parma: MUP.

(2017). "Introduzione". En Cinque ore con Mario. Versione teatrale, M. Delibes, 9-48. Venezia: Marsilio.

MARTÍNEZ, A. (1992). "Los codigos de la ironía en Cinco horas con Mario". Confluencia 7.1, 29-35.

MARTÍN GAITE, C. (1993). "Sexo y dinero en Cinco horas con Mario". En Miguel Delibes, Premio Letras Españolas 1991, Ministerio de Cultura (ed.), 387-410. Madrid: Ministerio de Educación, Cultura y Deporte (también en https://www.march.es/conferencias/ anteriores/voz.aspx?p1=22077 [10/05/2018]).

PERUGINI, C. (2016). "Narrazione e/o rappresentazione in Cinco Horas con Mario (con una coda afgana)". En Le forme del narrare: nel tempo e tra i generi II, E. Carpi et alii (eds.), 269-282. Trento: Università degli Studi di Trento / Dipartimento di Lettere e Filosofia. REY, A. (1975). La originalidad novelística de Delibes. Santiago de Compostela: Universidad.

ROMERA CASTILLO, J. (1981). "La literatura, signo autobiográfico. El escritor, signo referencial de su escritura". En La literatura como signo, J. Romera Castillo (ed.), 13-56. Madrid: Playor. (2004). "Actualidad y formas lingüísticas de la escritura autobiográfica en la España actual". En La memoria delle lingue (Atti del XXI Convengo Associazione Ispanisti Italiani), D. A. Cussato et alii (eds.) II, 9-35. Messina: Andrea Lippolis Editore. (2006). "Escritura autobiográfica de Miguel Delibes". En su obra, De primera mano. Sobre escritura autobiográfica en España (siglo XX), 279-290. Madrid: Visor Libros.

(2010). “Algo más sobre la escritura autobiográfica de Miguel Deli- 
bes". En Cruzando fronteras: Miguel Delibes entre lo local y lo universal, M. ${ }^{\text {a }}$ Pilar Celma Valero y José Ramón González (eds.), 113131. Valladolid: Cátedra Miguel Delibes.

SOBEJANO, G. (1981). "Estudio introductorio". En Cinco horas con Mario. Versión teatral, G. Sobejano (ed.), M. Delibes, 98-132. Madrid: Espasa-Calpe.

TABERNERO, R. M. (1987). "Cinco horas con Mario: de la novela al drama". Rilce 3.1, 95-107 (también en https://www.unav. edu/publicaciones/revistas/index.php/rilce/article/view/27212 [15/01/2019]).

UMBRAL, Francisco (1970). Miguel Delibes. Madrid: Epesa.

VALLES CALATRAVA, J. R. (2004). "Del papel a las tablas: el proceso transductivo de Cinco horas con Mario (novela, versiones, representaciones teatrales)". Revista de Literatura 66.132, 485502 (también en http://revistadeliteratura.revistas.csic.es/index. php/revistadeliteratura/article/download/130/141 [15/01/2019]).

Recibido el 9 de enero de 2019.

Aceptado el 6 de marzo de 2019. 